\title{
THE IMPACT OF EDUCATION ACROSS SECTORS AND THE MILLENNIUM DEVELOPMENT GOALS
}

\author{
Cresantus Biamba, Ph.D \\ Institute of International Education, Department of Education, Stockholm \\ University, Sweden
}

\begin{abstract}
The Millennium Development Goals (MDGs), which were agreed at United Nations General Assembly Millennium Summit in 2000, address challenges in poverty reduction, hunger, health, gender equality, education, and environmental sustainability, an ambitious set of development targets aimed at reducing poverty and improving the lives of people all around the world by 2015. Over the past decade, notable progress has been made on each individual MDG even in the poorest countries and the most difficult circumstances. Such success shows that the MDGs can be achieved. Indeed, the MDGs have led to unprecedented commitments, partnerships and progress in combating poverty and hunger, in improving school enrolment, in fostering gender equality and in extending equal access to health care. Yet progress is uneven between and within regions and countries and often too slow to meet the 2015 deadline. There is a growing realization that, without renewed commitment and concerted action, some countries will not reach all of the MDGs. In recent years there has been a growing body of literature on the interconnectedness of education and the Millennium Development Goals (MDGs). The purpose of this paper is to synthesize global evidence generated through various MDG Country Reports and supplementary documents that focus on trends toward progress and on the gaps and disparities that have arisen. The paper will help to establish a better understanding of how investment in education can lead to development outcomes that aid the achievement of the MDGs.
\end{abstract}

Keywords: Development, Education, Goals, Growth, Millennium, Outcomes, Poverty

\section{Introduction}

In recent years there has been a growing body of literature on the interconnectedness of the Millennium Development Goals (MDGs) and the 
need to maximize opportunities for education and their linkages. The existing empirical studies confirm some of the arguments about the benefits of education and the linkages to the MDGs. With the developmental outcomes of basic education in mind, this desk study set out to examine in what ways, and under what conditions investment in education is important in relation to the millennium development goals. It provides a synthesis of research on the potential contribution of basic education to achieving the MDGs, focusing on key texts produced by the international institutions. Within this review a key focal point will be the contextwithin which education appears to impact upon the various MDGs outcomes, which is refer to as the 'enabling environment'. The report will sought to explore the evidence about the contribution of basic education to poverty reduction and the achievement of the MDGs within certain countries or regions. It will also consider the critical support systems, policy environments and national capacities upon which good quality basic education depends, and assessed the role of basic education in developing and sustaining these. In response to the global call to achieve the MDGs by 2015, many countries are making remarkable progress demonstrating that setting bold, collective goals in the fight against poverty yields results. Expanding access and improving the quality of education are both imperative for MDG progress. A balance must be struck to move both objectives forward.

In response to the global call to achieve the MDGs by 2015, many countries are moving forward, including some of the poorest, demonstrating that setting bold, collective goals in the fight against poverty yields results. Robust economic growth in the first half of the decade reduced the number of people in developing regions living on less than $\$ 1.25$ a day from 1.8 billion in 1990 to 1.4 billion in 2005, while the poverty rate dropped from 46 per cent to 27 per cent (UN MDG Report, 2010). However, the global economic and financial crisis, which began in the advanced economies of North America and Europe in 2008, sparked abrupt declines in exports and commodity prices and reduced trade and investment, slowing growth in developing countries

Nevertheless, the collective efforts towards achievement of the MDGs have made inroads in many areas. Encouraging trends before 2008 had put many regions on track to achieve at least some of the goals. The economic growth momentum in developing regions remains strong and, learning from the many successes of even the most challenged countries, achieving the MDGs is still within grasp: Progress on poverty reduction is still being made, despite significant setbacks due to the 2008-2009 economic downturn, and food and energy crises. The developing world as a whole remains on track to achieve the poverty reduction target by 2015 . The overall poverty rate is still expected to fall to 15 per cent by 2015 - Which means 
around 920 million people living under the international poverty line half the number in 1990. But unmet commitments, inadequate resources, lack of focus and accountability, and insufficient dedication to sustainable development have created shortfalls in many areas. Moreover, as the UN MDGs Report 2010 points out, the effects of the global financial crisis are likely to persist: poverty rates will be slightly higher in 2015 and even beyond, to 2020, than they would have been had the world economy grown steadily at its pre-crisis pace.

\section{Education Outcomes and MDGs}

The positive economic impact of education is reflected in its contributions to increased national income and individual earnings. Rate of return studies have consistently shown a positive correlation between years of schooling and earnings, with higher returns resulting from schooling in low-income countries and investment in education for women and children from deprived groups. Recent evidence also shows that levels of cognitive andnon-cognitive skills acquired by students during schooling, rather than years of schooling, contribute most to increased income and lead to a more highly skilled workforce. Both PISA (Programme for International Student Assessment and TIMSS (Trends in International Mathematics and Science Study) cite improved workforce skills as a better predictor of economic growth than average levels of schooling. Many social development indicators are also positively associated with educational levels. Lastly, the present focus on universal primary education (UPE) and gender parity in the Millennium Development Goals (MDGs) places Education For All (EFA) within the framework of a 'collective endeavour to eliminate poverty. All of the foregoing points constitute good arguments and a solid rationale for investment in education and the expansion of educational provision.

Primary education is a powerful lever for poverty alleviation and social and economic growth (World Bank 2004). Its results can be empowering, enabling graduates to take charge of their lives and make more informed choices, contribute to the building of a democratic polity, increase earning potential and social mobility, improve personal and family health and nutrition (particularly for females), and enable women to control their fertility.It is widely stated that expanding education service is critical to making further progress on the MDGs, for broadening of growth, and for tackling persistent poverty and inequality (see ADB 2008, Kabeer 2010, UNICEF 2010, UN 2011). Various reports stress continuing disparities in MDG progress between different regions (especially between core and peripheral regions, urban and rural areas, and conflict-affected and peaceful regions). Within these under-served regions, various marginalised groups are persistently disadvantaged: women, certain minority ethnic or religious 
groups, and people with disabilities (see UN 2008, UN 2011, UNICEF 2010, Kabeer 2010).

Since the launch of the MDGs at the Millennium Summit in New York in September 2000, the MDGs have become a widely accepted yardstick ofdevelopment efforts by governments, donors and NGOs. The MDGs are a set of numerical and timebound targets related to key achievements in human development to be reached by 2015, from their levels in 1990. They include halving income-poverty and hunger, achieving universal primary education and gender equality, reducing infant and child mortality by three-quarters, and reversing the spread of HIV/AIDS and other communicable diseases. Almost all the countries in the world, have committed themselves to attaining the targets embodied in the Millennium Declaration by 2015.

\section{Linking Education, MDGs and Context The Eight Millennium Development Goals (MDG)}

\section{MDG 1: Eradicate extreme poverty and hunger \\ MDG 2: Achieve universal primary education \\ MDG 3: Promote gender equality and empower women \\ MDG 4: Reduce child mortality \\ MDG 5: Improve maternal health \\ MDG 6: Combat HIV/AIDS, malaria, and other diseases \\ MDG 7: Ensure environmental sustainability \\ MDG 8: Develop a global partnership for development}

Source: United Nations Development Group Guidance Note on MDG

Reporting, October 2003

\section{MDG 1: Eradicate extreme poverty and hunger}

MDG 1 focuses on efforts to reduce the number of people living in extreme poverty, generally defined as living on less than $\$ 1.25$ per day, to assure that able adults have jobs and to improve nutritional standards.

\section{Reducing Poverty and Achieving Sustainable Development}

At the 2005 World Summit, the international community reaffirmed its commitment to cut in half the number of people living in extreme poverty by 2015 and achieve the eight Millennium Development Goals (MDGs), a series of time-bound and quantified targets to attack poverty's root causes in a multi-dimensional way. The scale of the challenges, and the benefits of success to individuals, communities and the family of nation, are enormous: Global population is expected to increase from about 7billion today to 9.3 billion by 2050, and the population of the 48 Least Developed Countries will more than double to reach 1.7 billion. Almost all of the net increase in 
population is occurring in the urban areas developing countries, and in many of them, the number of people living in poverty is rising. Moreover, the supportive development environment that prevailed in the early years of this decade is now threatened as the world faces a global economic slowdown and a food security crisis. At the same time, the effects of climate change are becoming more apparent.

\section{Dimensions of poverty}

Substantial evidence suggests that slower population growth and investments in reproductive health and HIV prevention (particularly among adolescents), education, women's empowerment and gender equality reduce poverty. Carrying out the Programme of Action adopted at the International Conference Population and Development (ICPD) in Cairo and reaching its goal of universal access to reproductive health information and services by 2015 is an essential condition for achieving the MDGs. A central premise of the ICPD is that the size, growth, age structure and rural-urban distribution of a country's population have a critical impact on its development prospects and on the living standards of the poor. Poverty is multidimensional: impoverished people are deprived of services, resources and opportunities, as well as income. The ICPD realized that investing in people -- and empowering individual women and men with education, equal opportunities and the means to determine the number, timing and spacing of their children --could create the conditions to allow the poor to break out of the poverty trap.

Evidence from India suggests that higher starting rates of human capital can lead to more rapid rates of economic growth and poverty reduction (Ravallion \& Datt 2002). Research on India finds that government investments in education have a modest impact on poverty and productivity, but that investments in rural roads and agricultural research are more effective in this respect (Fan et al 2000). A similar study on China finds that government expenditure on education had the largest impact in reducing rural poverty and regional inequality and significant impact on production growth (Fan et al 2002). This finding that investing in human capital is more likely to drive poverty reduction and balanced growth than investment in physical capital is supported by a number of other studies on China (Hare \& West 1999, Heckman 2005, Fleischer et al 2008). Several studies estimate that extending basic services in poor countries can deliver large growth benefits, and that the return on investment associated with this expansion is good compared to other avenues of spending (Hutton et al 2006, Frontier Economics 2012). These estimates should however be treated with caution 


\section{Critical investments for poverty reduction}

Generally studies have shown that countries in which poverty levels are the highest are generally those that have the most rapid increases in population and the highest fertility levels. Countries that have reduced fertility and mortality by investing in universal health care, including reproductive health, as well as education and gender equality, have made economic gains. A 2001 study of 45 countries, for example, found that if they had reduced fertility by five births per 1,000 people in the 1980s, the average national incidence of poverty of 18.9 per cent in the mid-1980s would have been reduced to 12.6 per cent between 1990 and 1995.

\section{MDG 2: Achieve universal primary education}

The most important of the MDGs is to achieve universal primary education, one of the most recognized pillars of human development. The priorities contemplated by the MDGs are comprehensive and mutually reinforcing, so while enhancing education is a development goal by itself, it is also widely recognized as the main avenue of social mobility and, therefore, of escaping poverty (MDG1). MDG 2 focuses on education. Improved educational opportunities, especially starting with the earliest years, opens the doors to better income and advanced agricultural productivity, helps combat harmful legacy views of gender roles, allows people to make smarter choices surrounding health risks and behaviors and offers a broader view of the environment and global economy. MDG 2 centers on universal access to a full course of primary education. Several country case studies show a clear link between efforts to extend education to rural areas and improvements in school enrolment rates (MDG 2). Case studies on Cambodia (Engel \& Rose 2011), Benin (Engel \& Cossou 2011) and Ethiopia (Engel 2011) describe how targeted investments in rural education have contributed to rapid improvements in enrolment rates and more equitable service provision. These case studies find that these successes cannot be attributed entirely to programmes to extend services - they have also been assisted by broader improvements in governance and in social andeconomic development. They also stress that rapid increases in access levels have tended to be accompanied by a decline in quality.

A small number of studies have examined the broader economic benefits of extending education to people with disabilities. These studies (from Nepal, the US, South Africa, Bangladesh and Vietnam) find that extending education to people with disabilities has significant economic benefits, by increasing subsequent levels of employment and income (Lamichhane \& Sawada 2009). They also stress that inclusive education is more cost-effective than specialist provision for people with disabilities. 


\section{Wide-reaching impact}

Education has wide-ranging effects throughout society and links directly to poverty-reduction efforts. Poverty levels are lower among families in which the head of the household has had some education than in those where the head of the household has no education. In Serbia, the poverty level was three times the national average in households that were headed by someone with no education. Education is also directly related to improved health. In Syria in 2008, 77 percent of the mothers who had a child who died prematurely were illiterate or had not finished primary school. Educated mothers are also much more likely to have their children immunized.

\section{MDG 3: Promote gender equality and empower women}

Girls and boys have equal rights to quality education.According to DFID (2010) the fact that 39 million girls fail to attend primary school is both a tragedy for the girls themselves and a disaster for development. An increase of $1 \%$ in the number of girls with secondary education boosts annual per capita income growth by $0.3 \%$ and four years additional schooling lowers fertility rates. Access to education, through primary school and beyond, is also a critical factor in creating gender equality and, as more countries adopt the principle of universal primary education the focus is beginning to shift toward preventing girls from dropping out. "The main challenge is the ability to keep girls in school once enrolled, including up to secondary level and higher,” According to the MDG Country Report (2006) from Niger."This requires improvements in productivity among poor households to enable them to reduce the opportunity cost of sending girls to school. [...] Thus, this issue covers the whole challenge of reducing poverty."

In Ghana, where the MDG Country Report (2008) puts it on track to fulfilling MDG 3, the country has initiated some efforts that make remaining in school an attractive option for girls. Among these interventions are the construction of women's dormitories in secondary schools, the provision of school supplies [and] uniforms to needy girls, the sponsoring of scholarships for girls, the opening of 'gender-friendly' toilets and the offering of meals, including rations that can be taken home. "Active implementation of activities to promote girls' education has helped to eliminate barriers to enrolment and encouraged participation and attendance,” the Country Report states.

For many countries, major steps made toward gender equality have included drafting an appropriate legal framework and building representation of women on the national legislations that create those laws. The principles of gender equality have been written into the constitutions of some countries, but individual laws have often had to be changed or repealed altogether to 
reflect adequately the principles of gender equality set out in the Committee on the Elimination of Discrimination Against Women (CEDAW) and reflected in MDG 3. In many countries, legislation dealing with inheritance rights, land rights, asset ownership, access to credit and protection from violence, has been scrutinized and revised to ensure gender equality.

\section{MDG 4: Reduce child mortality}

Improved outcomes for women and children more education, lower fertility rates, higher nutritional status, and lower incidence of illness, among others have broad individual, family, and societal benefits (World Bank 2011). Though the evidence is thin on the causal relationship from maternal and child health to growth or poverty reduction, it is robust in establishing the intrinsic importance of general health to the individual and its instrumental importance as an input into the accumulation of human capital which in turn is a determining factor of economic growth (WHO 2002). Several studies point to a strong correlation between health and poverty (Strauss and Thomas 1998, Bloom and Canning 2000, WHO 2001, Gallup and Sachs 2001, Sachs and Malaney 2002). There is also evidence of a health-related poverty trap (Gallup and Sachs 2001, Bloom and others 2003, Bonds and others 2010).Despite the lack of good studies on the existence of a potential causal (instrumental) link between $\mathrm{MCH}$ and household or national wealth, maternal and child health is intrinsically valuable not only to mothers and children but also to the broader global community as is evident from the prominent placement of $\mathrm{MCH}$ in the Millennium Development Goals (MDGs). Child and maternal health now has a more prominent place on the international development agenda. The global initiatives on nutrition, child survival and maternal well-being announced at both the G8 summit in 2009 and the MDG summit in 2010 are welcome. However, current approaches fail to recognize the catalytic role that education - especially maternal education - can play in advancing health goals.

Equal treatment in education for girls and boys is a human right, and it is also a means of unlocking gains in other areas. Education improves child and maternal health because it equips women to process information about nutrition and illness, and to make choices and take greater control over their lives. Evidence from household surveys consistently points to maternal education as one for the strongest factors influencing children's prospects of survival. If the average child mortality rate for sub-Saharan Africa were to fall to the level for children born to women with some secondary education, there would be 1.8 million fewer deaths - a $41 \%$ reduction. In Kenya, children born to mothers who have not completed primary education are twice as likely to die before their fifth birthday as children born to mothers with secondary education or higher. 
The 2011 EFA Global Monitoring Report provides striking new evidence on the health benefits associated with maternal education. Using household survey data, it shows that, in many countries, mothers who are more educated are more likely to know that HIV can be transmitted by breastfeeding and that the risk of mother-to-child transmission can be reduced by taking medicines during pregnancy. In Malawi, $60 \%$ of mothers with secondary education or higher were aware that drugs could reduce transmission risks, compared with 27\% of women with no education. Quality education has also been a factor in reducing maternal and infant mortality rates. According to Gakidu et al. (2009) over half of the reduction in child mortality worldwide since 1970 is linked to "increased educational attainment in women of reproductive age.” Educated women are also more likely to seek out healthcare for themselves and their families. Studies on maternal health show that 90 percent of women with a secondary education in South and West Asia seek neonatal care, compared with only 50 percent of women with no education.

A case study of Bangladesh shows that improvements in targeting rural populations (Rodriguez Peres \& Samuel 2011) have led to rapid falls in child mortality (MDG 4). This study acknowledges that success in achieving these outcomes has also been underpinned by broader factors such as economic growth and cultural homogeneity. A programme-level impact evaluation in Ethiopia presents evidence that extending preventive and basic curative health services to previously under-served areas has led to an increase in the proportion of children vaccinated, but that the effect on preventive maternal care was limited and there was no broader decline in diarrhoea and cough diseases among children (Admassie et al 2009).

The 2011 MDG progress report claims that 'targeted interventions' in health have succeeded in reducing child mortality, with the number of deaths of children under the age of five having declined from 12.4 million in 1990 to 8.1 million in 2009, although no detail is provided about how this calculation was made (UN 2011).

\section{MDG 5: Improve maternal health}

Enabling people to have fewer children contributes to upward mobility and helps to stimulate development. When women can negotiate their reproductive health decisions with men, this exercise of their rights leads to an increased decision-making role within families and communities that benefits all. Because smaller families share income among fewer people, average per-capita income increases. Fewer pregnancies lead to lower maternal mortality and morbidity and often to more education and economic opportunities for women. These, in turn, can lead to higher family income. As women become more educated, they tend to have fewer children, and 
participate more fully in the labour market. Families with lower fertility are better able to invest in the health and education of each child. Spaced births and fewer pregnancies overall improve child survival.

Sexual and reproductive health services are key to curbing HIV. The pandemic is killing large numbers of people in their most productive years, increasing the ratio of dependents to the working-age population. Preventing AIDS-related disabilities and premature deaths translates into a healthier, more productive labour force that can improve a countrys economic prospects, many developing countries have large youth populations. Reproductive health programmes that address the greater vulnerability of adolescents to unprotected sex, sexual coercion, HIV and other sexually transmitted infections, unintended early pregnancies and unsafe abortions, and enable young women to delay pregnancy and marriage are important factors in breaking the intergenerational cycle of poverty. Investments in reproductive health, particularly in family planning, that result in lowered fertility can open a one-time only 'demographic window' of economic opportunity.

Evidence of the relationship between health status and education demonstrates that lower levels of educational attainment are associated with poorer health outcomes throughout life (Case, Fertig \& Paxson, 2005; Poulton et al., 2002; Sacker, Schoonb \& Bartleya, 2002). Level of education has been found to be a powerful predictor of mortality and overall morbidity across the lifespan (Lleras-Muney, 2005), with people who have not completed high school at risk of a shorter life compared with those who do complete (Muller, 2002; Sundquist \& Johansson, 1997). As well as being associated with a substantial reduction in educational outcomes, low socioeconomic status and poverty during childhood and adolescence are independent predictors of a number of illnesses including heart disease, cancer and diabetes(Albano et al., 2007; Kinsey, Jemal, Liff, Ward \& Thun, 2008; Raphael, 2006). Children from such backgrounds are more likely to miss school due to illness, have poorer school performance and overall lower expectations about their educational achievements (Jackson, 2009).The importance of early life experiences as a social determinant of health has been widely recognised by social researchers (for example, Raphael, 2006) and was endorsed in 2005 by the World Health Organisation, with the establishment of the Commission on Social Determinants of Health (World Health Organisation, 2010).

The foundations of adult health are determined in early childhood with the impact of early development and education setting the scene for future health outcomes and educational achievement. Poor emotional support and stimulation can lead to reduced readiness for school, low educational attainment, problem behaviour and the risk of social marginalisation in later 
life (Wilkinson \& Marmot, 2003). In most parts of the developing world children are disproportionately affected by poor health. The combined consequences of illness and social factors in this population have an adverse effect on educational outcomes for children, resulting in lower levels of achievement and attainment compared with other children (Schwab, 1999). There has been growing evidence over the last few decades of considerable disparities between poor and rich families across a number of health and social determinants (Ring \& Brown, 2003). Illnesses and diseases that are more prevalent among children from poor family background compared with children from rich family contribute to a considerable burden of disease among these children and their families (Thomson et al., 2010). In addition, psychosocial factors such as overcrowded housing, domestic violence, greater interaction with the justice system, and alcohol and substance use negatively affect health status and mental and emotional well-being (Bailie \& Runc, 2001).

Other indices such as life expectancy, the rate of teenage pregnancies, and infant and maternal mortality demonstrate poorer outcomes for families with low incomes (Thomson et al., 2008). Health status and educational achievement are inextricably linked but, for the most part, the two sectors operate independently of each other in the provision of health and educational services.

\section{MDG 6: Combat HIV/AIDS, malaria and other diseases}

MDG 6 calls on countries to stop and reverse the spread of HIV/AIDS and to secure universal access to antiretroviral drugs for people living with HIV/AIDS by 2015. For many countries fighting their way out of poverty, the ravages of HIV/AIDS represent not only a singular health crisis, but also the single greatest obstacle to economic growth and well-being. In 2008, sub-Saharan Africa accounted for almost three quarters of the global deaths related to AIDS and for about two thirds of those infected with HIV worldwide. In Asia, about 6 million households will sink into poverty between 2008 and 2015 as a result of the economic consequences of AIDS, based on an estimate by the Commission on AIDS in Asia.

Despite significant gains in universal access to treatment, significant gaps remain for most countries. And with new infections outpacing treatment scale-up for every two people put on treatment, five more are newly infected along with millions of AIDS orphans, AIDS is indeed a long-wave event, one that countries will have to address for many years to come. MDG 6 also takes into account efforts to combat malaria, tuberculosis and other deadly diseases, striving to halt or reverse the spread of these diseases by 2015 . 


\section{The role of education in HIV prevention}

Education has been identified as a key element in HIV prevention; even in the absence of HIV-specific interventions, education was seen to offer an important protection against HIV. The Global Campaign for Education (2004), for instance, estimated that universal primary education alone would prevent 700,000 new HIV infections each year. More recent studies and reviews find similar evidence: in their systematic review, Hargreaves et al (2008), for instance, find a tendency for higher HIV prevalence rates to be associated with the least educated in sub-Saharan Africa. Similarly, in their study in South Africa, Hargreaves et al (2008b) also found that attending school can be associated with lower-risk sexual behaviours; lower HIV prevalence among young men; and that secondary school attendance may influence the kinds of sexual relationships in which young people engage and thereby can also reduce HIV risk. They conclude generally that school attendance may reduce HIV transmission among young people.

\section{The role of HIV and AIDS-related education}

Given that education per se is a protective factor against HIVacquisition, HIV-specific interventions within educational / learning environments, are likely to have an even greater protective effect. And indeed, a number of studies conclude that there is sufficient evidence to support wide-spread implementation of school-based HIV related interventions (e.g. UNAIDS, 2011; Kirby et al, 2006; Ross et al., 2007; Harrison et al, 2010). In their systematic review, for instance, Mavedzenge, et al (2010 and 2011) conclude that school-based, adult-led, curriculumbased interventions showed clear evidence of reductions in reported risky sexual behavior; similarly, Yankah and Aggleton (2008) state that "Overall, effective interventions were shown to have positive effects on knowledge, attitudes, skills and sometimes on behaviours” (pg 468).

For young women, who in many countries are particularly vulnerable to HIV and AIDS, a recent literature review concludes that one way to empower them to assert their sexual and reproductive rights is by increasing access to education, particularly secondary education (Hargreaves and Boler, 2006). More broadly it can be argued that HIV and AIDS-related education is critical for young people since it provides them with information before they become sexually active or potentially engage in risk behaviors, including drug use (see also World Bank, 2002 and 2010). For young people who are already sexually active or using drugs, such education can also help protect them through providing information and knowledge about where and how to seek help, information and services. 


\section{MDG 7: Ensure environmental sustainability}

MDG 7 takes a longer-term view of national development and efforts to reduce poverty, to ensure food security and to create the infrastructure needed to underpin social and health care advances. In doing so, it considers the protection of natural resources and an area's biodiversity. In addition, this Millennium Goal calls for significantly better access to safe drinking water and basic sanitation, as well as improved living conditions for people living in slums. The Country Reports show that, although there has been progress toward these targets, many countries are struggling with environmental sustainability. In addition, MDG 7 has produced a wide range of ambiguity, with data often insufficient to allow assessment of the status.

A study comparing the impact of Dutch assistance on water and sanitation programmes in a number of countries finds that rural water programs are broadly beneficial to poor communities and that the poorest people usually enjoy the benefits of improved water supplies. It also finds, however, that the very poorest and most marginalized communities typically have less access to these programs and benefit less from them (MFA Netherlands 2012). A few studies have estimated that there are considerable economic benefits associated with improving access to water and sanitation (Hutton et al 2006, Frontier Research 2012).

An impact evaluation study shows that two water supply and sanitation projects in rural Pakistan improved households' access to water supply and improved school attendance among high-school-age girls. However, the projects had no significant impact on the incidence and intensity of diarrhea and on increasing labour force participation and hours available for work (Rauniyar et al 2011). Several other case studies (Uganda, Ghana, and Ethiopia) show that targeted efforts to improve rural water and sanitation have been successful (MDG 7C), though these studies do not examine broader impacts of these interventions on health outcomes, poverty reduction, or economic growth.

\section{MDG 8: Develop a global partnership for development}

The final Millennium Goal takes broader view of development that supports national efforts to achieve the other MDGs. Among a diverse set of targets within MDG 8 that range from internet access to flows of official development assistance, one of the clear priorities encouraged by the Millennium Goal is integration with the global economy with equal opportunities through market access, international cooperation, debt policies and fiscal acumen. In the current volatile global environment, progress toward individual goals is difficult to assess. 


\section{Conclusion}

Investing in education will be central to addressing $21^{\text {st }}$ century challenges, including global competitiveness, climate change, conflict and insecurity. This is a two-way relationship. While measures are needed to counter the negative impact of economic recession, climate change and conflict on education, education must offer its own ways of combating and responding to the wider economic, environmental and social threats. If it fails to do so, educational gains will be lost, and education will quickly lose its relevance.

In our knowledge-based world, education is the single best investment countries can make towards building prosperous, healthy and equitable societies. It unleashes the optimal potential in people, improving individual livelihoods and those of future generations. If all students in lowincome countries acquired basic reading skills, 171 million people could be lifted out of poverty, equivalent to a $12 \%$ cut in world poverty. By expanding educational opportunities, we can open the door to more equitable, dynamic and resilient patterns of globalization. It will be difficult to achieve sustainable development or lasting peace without the knowledge, skills and values cultivated through education. Indeed, education is the critical thread tying together all our hopes for the achievement of the Millennium Development Goals (MDGs).

\section{References:}

Admassie, A. (2009) 'Impact evaluation of the Ethiopian Health Services Extension Programme', Journal of Development Effectiveness, Vol.1, No. 4. Asian Development Bank (ADB), 2008, 'Equity in the Delivery of Public Services in Selected Developing Member Countries', Regional Technical Assistance Report.

Bloom, E. and Canning, D (2001). "The Health and Wealth of Nations." Science, no. 5456.

Bonds M., Keenan D., Pejman R. and Sachs, J. (2010). "Poverty Traps Formed by the Ecology of Infectious Diseases." Proceedings of theRoyal Society of Biological Sciences, no. 277.

Case, A., Fertig, A., \& Paxson, C. (2005). The lasting impact of childhood health and circumstance. Journal of Health Economics, 24, 365-389.

DFID. (2010). Globalization, education and development: ideas, actors and dynamics. Researching the issues. No.68 Department of International Development.

Engel, J. (2011) 'Ethiopia's progress in education: A rapid and equitable expansion of access', ODI.

Engel, J. and Rose, P. (2011) 'Rebuilding basic education in Cambodia: Establishing a more effective development partnership', ODI 
Engel, J. with Cossou, M. (2011) 'Benin's progress in education: Expanding access and closing the gender gap', ODI

Fan, S., Hazell, P \& Thorat, S. (2000) 'Government Spending, Growth and Poverty in Rural India', American Journal of Agricultural Economics, Vol.82. No 4.

Fan, S., Zhang, L., Zhang, X. (2002) 'Growth, Inequality, and Poverty in Rural China: The Role of Public Investments', International Food Policy Research Institute, Research Report 125, Washington DC.

Fleisher, M.; Haizheng, L. \& Min Qiang, Z (2008) 'Human capital, economic growth, and regional inequality in China', IZA DiscussionPapers, No. 3576,

Frontier Economics (2012) 'Exploring the links between water and economic growth'. A report prepared for HSBC by Frontier Economics

Gallup, J. and Sachs, J. 2001. "The Economic Burden of Malaria.” American Journal of Tropical Medicine and Hygiene, no. 64.

Gakidu, E. (2009) "Increased Educational Attainment and its Effect on Child Mortality in 175 Countries Between 1970 and 2009: A Systematic Analysis." The Lancet 376 (2010):. 959-974.

Hanushek, E. A., \& Zhang, L. (2006). Quality-consistent estimates of international returns to skills. NBERWorking Paper 12664. Cambridge, Mass.: NationalBureau of Economic Research

Harrison, A., Newell, J. Imrie \& G. Hoddinott, (2010). HIV prevention for South African youth: which interventions work? A systematic review of current evidence. BMC Public Health, 10:102

Heckman, J. (2005) 'China's human capital investment', China EconomicReview, Vol. 16, pp.50-70.

Hutton, G., Haller, L., and Bertram, J. (2006) 'Economic and health effects of increasing coverage of low cost water and sanitation interventions', Human Development Report Office Occasional Paper.

Jackson, M. (2009). Understanding links between adolescent health and educational attainment. Demography, 46(4), 671-694.

Kinsey, T., Jemal, A., Liff, J., Ward, E., \& Thun, M. (2008). Secular trends in mortality from common cancers in the United States by educational attainment, 1993-2001. Journal of the National Cancer Institute, 100(14), 1003-1012.

Kirby, D., Obasi, A. and Laris, B. (2006), 'The effectiveness of sex education interventions in schools in developing countries', in UNAIDS Task Team on Young People, Preventing HIV/AIDS in Young People, pp.103-150

Kabeer, N. (2010) 'Can the MDGs provide a pathway to social justice? The challenge of intersecting inequalities', Institute of Development Studies and the MDG Achievement Fund. 
Lamichhane, K. and Sawada, Y. (2009) 'Disability and Returns to Education in a Developing Country', READ Discussion Paper.

Lleras-Muney, A. (2005). The relationship between education and adult mortality in the United

Mavedzenge, S; Doyle, A and Ross, D (2011). HIV Prevention in Young People in Sub Saharan Africa: A Systematic Review Journal of Adolescent Health, Vo 4, issue 6, Pages 568-586.

Ministry of Foreign Afairs, Netherlands (2012) 'Rural Sanitation and Water: Assessing Impacts', Evaluation Insights, OECD.

Muller, A. (2002). Education, income inequality, and mortality: A multiple regression analysis. British Medical Journal, 324, 1-4.

OECD (2011), "What are the social outcomes of education?”, in Education at a Glance 2011: OECD Indicators, OECD Publishing.

OECD (2011) Education at a Glance: OECD Indicators

OECD (2011) 'Special Focus: Inequality in Emerging Economies (EEs)' in Divided We Stand: Why Inequality Keeps Rising'. OECD

OECD (2010), Improving Health and Social Cohesion through Education, Paris.

OECD (2007), Understanding the Social Outcomes of Learning, OECD, Paris.

Poulton, R., Caspi, A., Milne, B., Thomson, M., Taylor, A., Sears, M., et al. (2002). Association between children's experience of socioeconomic disadvantage and adult health: A life course study. Lancet, 360, 1640-1645.

Raphael, D. (2006). Social determinants of health: present status, unanswered questions, and future directions. International Journal ofHealth Services, 36(4), 651-677.

Rauniyar, G., Orberta, G., Sugiyarto, G. (2011) 'Impact of water supply and sanitation assistance on human welfare in rural Pakistan', Journal ofDevelopment Effectiveness, Vol. 3, No. 1.

Ravallion, M. and Datt, G. (2002) 'Why has economic growth been more pro-poor in some states of India than others?', Journal ofDevelopment Economics, Vol. 68, pp. 381-400.

Ring, I., \& Brown, N. (2003). The health status of indigenous peoples and others. British Medical Journal, 327, 404-405.

Rodriguez Pose, R. and Samuels, F. (2011) 'Bangladesh's progress in health: Healthy partnerships and effective pro-poor targeting', Overseas Development Institute.

Ross, D., Changalucha, J., Obasi, A., Todd, J., Plummer, M., CleophasMazige, B., et al. (2007). Biological and behavioral impact of an adolescent sexual health intervention in Tanzania: A community-randomised trial. AIDS, 21, 1943-1955. 
Sacker, A., Schoonb, I., \& Bartleya, M. (2002). Social inequality in educational achievement and psychosocial adjustment throughout childhood: Magnitude and mechanisms. Social Science andMedicine, 55, 863-880.

Sachs, J. and Malaney, P. (2002). "The Economic and Social Burden of Malaria.” Nature, no. 415.

Schwab, R. (1999). Why only one in three? The complex reasons for low Indigenous school retention. Centre for Aboriginal Economic Policy Research, Research Monograph No.16. Canberra: Australian National University.

Strauss, J. and Thomas, D. (1998). "Health, Nutrition and Economic Development.” Journal of Economic Literature, no. 36.

Sundquist, J., \& Johansson, S. (1997). Self reported poor health and low educational level predictors for mortality: A population based follow up study of 39156 people in Sweden. Journal of Epidemiology andCommunity Health, 51, 35-40.

UNAIDS (2011), Securing the future today. Strategic information on HIV and young people

UN (2011) 'The Millennium Development Goals Report 2011”, United Nations, New York.

UN (2008) 'The Millennium Development Goals Report 2008', United Nations, New York.

UNESCO, 2011. School-Based Sexuality Education Programmes: A cost and cost-effectiveness analysis in six countries. Paris: UNESCO

UNESCO (2005) 'Regional overview: Sub-Saharan Africa', Global Monitoring Report - Literacy for Life, Paris: UNESCO.

UNDP. (2010). Human Development Report. New York

UNICEF (2010) 'Progress for Children: Achieving the MDGs with Equity', Number 9, September 2010.

Wilkinson, R., \& Marmot, M. (2003). Social determinants of health: Thesolid facts (2nd ed.).

World Health Organisation. (2010). Social determinants of health. Retrieved from http://www.who.int/social_determinants/en/

World Health Organization (2001). "Macroeconomics and Health: Investing in Health for Development Report of the Commission on Macroeconomics and Health." Geneva.

World Bank Global Monitoring Report (2012). Food, Nutrition, and theMillennium Development Goals.” Washington, DC.

World Bank Global Monitoring Report (2011). Linking Spending andOutcomes." Washington, DC: World Bank.

World Bank, (2010). Accelerating the Education Sector Response to HIV: Five Years of Experience from Sub-Saharan Africa. 
World Bank (2004) 'Mexico's Oportunidades Program', Case study presented at the World Bank Shanghai conference on its Reducing Poverty: Sustaining Growth initiative.

World Bank. (2002). Education and HIV/AIDS: A Window of Hope. Washington, DC: World Bank.

Yankah, E. and P. Aggleton, (2008). Effects and Effectiveness of Life Skills Education for HIV prevention in Young People. AIDS Educationand Prevention, 20(6), 465-485, 2008. 